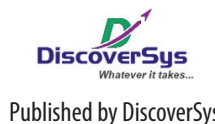

Published by DiscoverSys

\section{Meningkatkan Daya Saing Tenaga Kesehatan dalam Era Masyarakat ASEAN}

\author{
Dewa Nyoman Wirawan ${ }^{1,2^{*}}$
}

${ }^{1}$ Program Studi Magister IImu Kesehatan Masyarakat Universitas Udayana,

${ }^{2}$ Bagian IImu Kedokteran Komunitas dan IImu Kedokteran Pencegahan Fakultas Kedokteran Universitas Udayana

*Korespondensi penulis: Dewa Nyoman Wirawan, Program Studi Magister IImu Kesehatan Masyarakat Universitas Udayana, Bagian IImu Kedokteran Komunitas dan IImu Kedokteran Pencegahan Fakultas Kedokteran Universitas Udayana

wirawandewa48@gmail.com
Pada tahun 2003, kepala negara-negara ASEAN telah sepakat bahwa Masyarakat ASEAN akan terwujud pada tahun 2020. ${ }^{1}$ Masyarakat ASEAN terdiri dari tiga pilar yaitu: ASEAN Political-Security Community, ASEAN Economic-Community dan ASEAN Socio-Cultural Community. ${ }^{1}$ Tujuan yang ingin dicapai adalah: a) terciptanya kawasan tunggal dalam hal produksi dan arus barang; b) kawasan ASEAN yang mempunyai daya saing tinggi dalam bidang ekonomi; c) kawasan ASEAN dengan pertumbuhan ekonomi yang seimbang (equitable); dan d) kawasan yang secara penuh mampu berintegrasi dengan ekonomi global. ${ }^{1}$ Pada tahun 2007, kepala negara-negara ASEAN berkomitmen untuk mempercepat terwujudnya Masyarakat ASEAN pada akhir tahun 2015. ${ }^{1}$ Berkaitan dengan ASEAN Economic-Community yang telah disepakati integrasinya akan terwujud pada akhir tahun 2015, terdiri dari liberalisasi sektor perdagangan, jasa, investasi, tenaga terampil dan pasar modal. Berkaitan dengan liberalisasi tenaga terampil, ada 8 profesi yang telah disepakati dalam Mutual Recognition Arrangements (MRA) yaitu: akuntansi, teknik, survei, arsitektur, keperawatan, kesehatan, perawatan gigi dan pariwisata. ${ }^{1}$ Sebagai tindak lanjut kesepakatan MRA, Pemerintah Indonesia telah melaksanakan sejumlah langkah antara lain melakukan sertifikasi tenaga profesi dan menerapkan Kerangka Kualifikasi Nasional Indonesia (KKNI) seperti tertuang dalam Peraturan Presiden Nomor 8 Tahun 2012 tentang Kerangka Kualifikasi Nasional Indonesia. ${ }^{2}$

Dalam MRA tentang tenaga perawat dan dokter tercantum bahwa tenaga kesehatan bisa bekerja di setiap negara ASEAN dengan syarat harus mengikuti peraturan yang telah ditetapkan di masing-masing negara seperti tercantum di Article III masing-masing MRA yang antara lain disebutkan bahwa bila tenaga keperawatan atau kesehatan akan bekerja di negara-negara ASEAN maka harus mengikuti undang-undang atau peraturan di host country (in accordance with the laws and regulations of the host country concerned). ${ }^{3,4}$

Untuk meningkatkan daya saing tenaga kesehatan Indonesia dari kemungkinan masuknya tenaga kesehatan luar negeri, Pemerintah Indonesia telah menerbitkan beberapa regulasi antara lain: a) Undang-Undang Republik Indonesia Nomor 36 Tahun 2014 Tentang Tenaga Kesehatan; ${ }^{5}$ b) Peraturan Menteri Kesehatan Republik Indonesia Nomor
67 Tahun 2013 Tentang Pendayagunaan Tenaga Kesehatan Warga Negara Asing di Indonesia; ${ }^{6}$ dan c) Undang-Undang Republik Indonesia Nomor 44 Tahun 2009 Tentang Rumah Sakit. ${ }^{7}$ Sedangkan untuk meningkatkan daya saing tenaga profesional Indonesia termasuk tenaga kesehatan, Pemerintah Indonesia telah menerbitkan Peraturan Presiden Nomor 8 Tahun 2012 tentang Kerangka Kualifikasi Nasional Indonesia (KKNI). ${ }^{2}$ Untuk mendapatkan Surat Tanda Registrasi (STR) seperti tercantum dalam Undang-Undang Republik Indonesia Nomor 36 Tahun 2014 dan Peraturan Menteri Kesehatan Republik Indonesia Nomor 67 Tahun 2013 dilakukan ujian kompetensi dalam Bahasa Indonesia., ${ }^{5,6}$ Selain itu, standar gaji tenaga kesehatan warga negara asing umumnya lebih tinggi dibanding standar gaji tenaga kesehatan dalam negeri dan jumlah lulusan di dalam negeri juga melebihi kebutuhan fasilitas pelayanan kesehatan yang ada di Indonesia, terutama di daerah perkotaan. Malaysia dan Singapura saat ini masih kekurangan tenaga kesehatan terutama tenaga perawat, ahli laboratorium kesehatan, rekam medis, teknisi gigi, gizi, radiologi, elektro medik, dan fisioterapis. Selain di fasilitas pelayanan kesehatan, banyak negara seperti Singapura, Jepang, Taiwan dan Korea juga memerlukan tenaga care giver (perawat di rumahtangga) yang berpeluang diisi oleh tenaga kesehatan Indonesia. Karena itu, bila dipersiapkan dengan baik, maka tenaga kesehatan Indonesia akan lebih berpeluang untuk bekerja di luar negeri dibandingkan tenaga kesehatan negara lain bekerja di Indonesia.

Selain regulasi dan kebijakan yang telah dikembangkan oleh pemerintah pusat, peran pemerintah provinsi/kab/kota dan lembaga pendidikan juga amat penting untuk meningkatkan daya saing tenaga kesehatan. Pertama, mengembangkan sistem pemantauan (surveilans) tenaga kerja asing di wilayahnya masing-masing, bekerja sama dengan instansi terkait terutama pihak imigrasi. Walaupun telah ada Undang-undang Tentang Pendayagunaan Tenaga Kesehatan Warga Negara Asing di Indonesia, kemungkinan masuknya tenaga kesehatan asing secara ilegal masih amat memungkinkan. Kedua, pemerintah provinsi/ kab/kota terutama dinas kesehatan bekerja sama dengan instansi terkait, juga perlu memantau dengan ketat standar mutu lulusan lembaga pendidikan kesehatan di daerahnya masing-masing 
agar sesuai dengan standar kompetensi yang telah ditetapkan. Hal ini sesuai dengan tanggung jawab dan kewenangan pemerintah provinsi/kab/kota yang diatur dalam Pasal 6 dan 7 Undang-Undang Republik Indonesia Nomor 36 Tahun 2014. ${ }^{5}$ Ketiga, untuk meningkatkan kesempatan tenaga kesehatan bekerja di luar negeri, pemerintah daerah, terutama dinas tenaga kerja perlu menjalin hubungan dengan para konsulat negara sahabat yang ada di daerahnya masing-masing dan dengan Pelaksana Penempatan Tenaga Kerja Indonesia Swasta (PPTKIS). Hal ini sejalan dengan Rencana Pengembangan Tenaga Kesehatan Kementerian Kesehatan Tahun 20112025. ${ }^{8}$ Keempat, pemerintah provinsi/kab/kota terutama dinas kesehatan perlu menjalin hubungan dan melakukan sosialisasi dengan lembaga pendidikan kesehatan di wilayahnya masing-masing tentang standar dan kualifikasi tenaga kesehatan di negara-negara ASEAN. Hal ini sejalan dengan tujuan ASEAN MRA on Nursing Services yaitu tentang butir exchange information and expertise on standards and qualifications. Kelima, pemerintah provinsi/kab/kota serta semua lembaga pendidikan bidang kesehatan perlu menjalin hubungan dengan negara-negara ASEAN dalam upaya untuk meningkatkan kapasitas tenaga kesehatan dimana hal ini sejalan dengan tujuan ASEAN MRA yaitu tentang tujuan provide opportunities for capacity building and training of nurses. Keenam, semua lembaga pendidikan bidang kesehatan harus meningkatkan kompetensi dan kemampuan Bahasa Inggris atau bahasa asing lainnya bagi para mahasiswanya.

\section{DAFTAR PUSTAKA}

1. ASEAN Secretariat, ASEAN Economic Community Factbook. 2011. Jakarta, Indonesia.

2. Peraturan Presiden Nomor 8 Tahun 2012 tentang Kerangka Kualifikasi Nasional Indonesia. Available from URL: http/www.http://sipuu.setkab.go.id/PUUdoc/17403/ Perpres0082012.pdf.

3. ASEAN Mutual Recognition Arrangement on Nursing Services. Available from URL: http://www.asean.org/ communities/asean-economic-community/item/aseanmutual-recog-nition-arrangement-on-nursing-services.

4. ASEAN Mutual Recognition Arrangement on Medical Practitioners. Available from URL: http://www.globalhealthaction.net/index.php/gha/article/ download/24535/pdf_1.

5. Undang-Undang Republik Indonesia Nomor 36 Tahun 2014 Tentang Tenaga Kesehatan. Available from URL: http://www.hukor.depkes.go.id/up_prod_uu/UU\%20 No.\%2036\%20 Th\%202014\%20ttg\%20 Tenaga\%20 Kesehatan.pdf.

6. Peraturan Menteri Kesehatan Republik Indonesia Nomor 67 Tahun 2013 Tentang Pendayagunaan Tenaga Kesehatan Warga Negara Asing. Available from URL: http://bppsdmk. depkes.go.id/web/filesa/peraturan/21.pdf.

7. Undang-Undang Republik Indonesia Nomor 44 Tahun 2009 Tentang Rumah Sakit. Available from URL: http://binfar. kemkes.go.id/?wpdmact=process\&did=MTY 1 Lmhvd Gxpbms=.

8. Tim Koordinasi dan Fasilitasi Pengembangan Tenaga Kesehatan. Rencana Pengembangan Tenaga Kesehatan Tahun 2011-2025. Jakarta, 2011. Available from URL: http:// perpustakaan.depkes.go.id:8180/handle/123456789/ 2131.

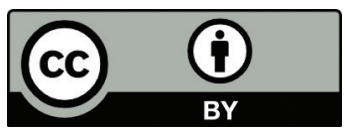

This work is licensed under a Creative Commons Attribution 